\title{
Prêt-à-Porter, discussões em torno de seu surgimento e relação com a Alta-Costura francesa
}

\author{
Prêt-à-porter, discussions on its rise and relation to the French Haute Couture
}

\author{
SANT'ANNA-MULLER, Mara Rubia \\ Doutora em História; Universidade do Estado de Santa Catarina - UDESC \\ sant.anna.udesc@gmail.com
}

\begin{abstract}
Resumo
Estudo histórico sobre o contexto do surgimento do Prêt-à-porter na França, pós Segunda Guerra Mundial e o seu significado dentro do sistema mundial de Moda. É relacionado o projeto político de manutenção de Paris como capital mundial da moda, as demandas dos novos grupos sociais de elite, a crise vivida pelas Casas de Alta-Costura e o significado atribuído à elegância. A metodologia de pesquisa centrou-se na análise discursiva e na teoria da estética do efeito histórico, tendo como fonte principal as matérias e editoriais da Revista Elle, publicados entre 1950 e 1970.
\end{abstract}

Palavras Chave: Prêt-à-porter; Sociedade pós Segunda Guerra Mundial; Moda Francesa e Sistema de moda.

\begin{abstract}
Historical study on prêt-à-porter rise context in France after the Second World War, and its meaning within the World's Fashion System. This article relates the political project of Paris maintaining as world capital of fashion, the demands of the new elite social groups, the crisis experienced by the Couture Maisons and the meaning given to the elegance. The research methodology focused on the discursive analysis and on the theory of the historical effect aesthetic, having as main sources articles and Elle Magazine editorials, published between 1950-1970.
\end{abstract}

Keywords: Prêt-à-porter; Society's after the Second World War; French fashion. Fashion system.

\section{Introdução}

Este estudo desdobrou-se da Tese de Doutorado defendida em 2005 e centrou-se sobre a análise da situação histórica francesa entre 1950 e 1970, especificamente, no tocante a sua estrutura econômica no setor da produção do luxo vestimentar e diante do seu projeto político de manter-se como capital mundial da moda. Como fonte histórica investigou-se as maiores revistas francesas especializadas no assunto, sobretudo, os volumes de janeiro de 1950 a dezembro de 1970 do Magazine Elle, dados estatísticos e outros levantamentos históricos, produzidos por pesquisadores franceses.

Além da leitura e seleção dos editoriais que evidenciassem as mudanças projetadas e realizadas, o que o próprio teor dos títulos e textos dava conta de destacar, foram estudados dados quantitativos e estudos já concluídos sobre as mudanças culturais vividas pelos franceses no respectivo período. Por meio destes dados foi feito estudo comparativo entre o que as revistas salientavam em suas matérias e aquilo vivido e atestado como média ponderada à

Projética Revista Científica de Design I Universidade Estadual de Londrina I V.2 I N.2 I Dezembro 2011 
Prêt-à-Porter, discussões em torno de seu surgimento e relação com a Alta-Costura francesa população francesa. Com estes parâmetros impunha-se leitura crítica do que havia sido escrito nas revistas pesquisadas, identificando a origem dos significados expressos.

A proposta metodológica da estética do efeito histórico, adotada igualmente como pressuposto teórico, impõe o conhecimento do universo de significantes que interferem tanto na poética como na recepção das mensagens, para que seja possível a interpretação das propostas discursivas dos textos.

Os editoriais, reportagens e artigos encontrados no Magazine Elle ofereceram um campo discursivo intenso no qual a defesa de uma "nova" Haute-Couture francesa se fazia evidente. Dentre as argumentações analisadas, o tom nacionalista tomava muitas páginas e recorreu, incessantemente, à defesa da mudança da estrutura de produção do luxo vestimentar para que Paris e a França não perdessem seu prestígio junto às elites mundiais, como analisado em seguida. Não apenas discursos, porém, constituem os processos históricos, pois se eles direcionam e reconstroem significados, são as práticas sociais que dão conteúdo e repercussão às ideias. Portanto, enquanto Elle professava suas ideias em sintonia com a emergência de modernizar a França, a sociedade francesa engendrava novas práticas que reconfiguravam novos significados e tendências de moda.

\section{O Contexto}

A Haute-couture francesa, instituída em meio ao século XIX, cooperou para o fortalecimento e a expansão da indústria do luxo, sobre a qual a França detinha a hegemonia desde os primórdios da Idade Moderna. Considerada como fator econômico e de identidade nacional francesa dos mais relevantes, sempre conquistou as graças da imprensa nacional, como também as benesses do governo.

Quando da Ocupação discursos de resistência pacífica foram elaborados a partir da imagem da Haute-couture e da elegância da mulher parisiense, visando manter a identidade nacional viva, ao mesmo tempo em que alimentava a esperança em dias melhores, impedindo a invasão cultural (VEILLON, 2004). Terminada a Guerra, em 1945, e restituída a liberdade ao território francês, uma grande empreitada nacional foi acionada, visando a reconquista dos mercados internacionais da Haute-couture. A missão da exposição "Le Théâtre de la Mode", organizada entre 1945 e 1946, por iniciativa de Roberto Ricci, com apoio do Ministro Raoul Dautry e promovida pela Câmara Sindical da Costura parisiense, foi a de demonstrar ao mundo que, apesar da Guerra, a Haute-couture francesa não havia morrido. Além do pavilhão de Marsan, no interior do Louvre, esta exposição viajou pelo mundo, indo a Londres, Barcelona, Copenhague, Estocolmo, Viena e a Nova lorque, com 13 cenários assinados pelos mais renomados artistas franceses da época e 237 bonecas, vestidas com o que havia de melhor e mais criativo da genialidade de diversos criadores da Haute-couture francesa. (ROCHAS, 1951).

Dior, consagrado a partir de 1947 com sua coleção rebatizada de New Look, cooperou na reafirmação que Paris e a França poderiam continuar a representar a elegância mundial e que nenhuma elite mondial podia se definir como tal, sem possuir seus exemplares de criação da Haute-Couture.

Contudo, dos primeiros anos pós Segunda Guerra Mundial ao surgimento do Prêt-àporter uma outra sociedade mundial foi configurada (ELIAS, 1994; HOBSBAWN, 1995) devido aos avanços tecnológicos ocorridos e, principalmente, à hegemonia cultural e econômica dos Estados Unidos da América. Os anos pós-guerra, aos poucos, elaboraram uma nova sociedade, cujos valores eram representados com fragilidade pela Haute-couture francesa tradicional. 
Mara Rubia Sant'anna-Muller

Givenchy, Balenciaga, Fath, Lanvin e Rouff são alguns dos grandes costureiros que conviveram com Dior e partilharam com ele a construção de uma ideia de elegância vinculada a um corpo e gestual bem cuidado. Contudo, na medida em que os anos 60 chegaram, observa-se modificações significativas nas tendências que todos os grandes costureiros apresentaram. Em grande parte, isso decorreu diretamente do falecimento ou afastamento do criador da direção de sua Maison e a chegada de outros profissionais, que os substituíram. Porém, o fato de maior relevância está no redimensionamento do significado do papel da Haute-couture na produção da elegância idealizada, o que exigiu de seus novos profissionais outros perfis. Tal contexto exigiu das Maisons maior flexibilidade face aos novos grupos sociais que se constituíam a partir de outros poderes aquisitivos no cenário mundial. Na dança do poder, foi preciso abrir espaço para novos pares.

\section{A Haute-couture em xeque}

Dentro deste contexto de transformações significativas que França passava, após a Segunda Guerra Mundial, a proposta de existência e missão que a revista Elle se atribuía foi representativa. Editada por Hélène Gordon-Lazareff, sua diretora-presidente, que havia amadurecido profissionalmente em Nova lorque e nos bastidores da Vogue e contando com Françoise Vincent-Ricard em sua equipe, a revista tinha como meta trazer o "espírito do business nova-iorquino para Paris e adequar a leitora da revista a um estilo mais moderno de viver".

A história profissional dessas mãos que conduziam a existência da revista Elle dimensiona o valor desta fonte histórica. Vincent-Ricard, em depoimento sobre sua experiência profissional, relatou sua primeira viagem à Nova lorque ao lado de Hélène Lazareff, no começo dos anos 50, e o choque que viveu pela distância cultural entre as duas cidades. Segundo suas memórias, a partir daquele momento, deu-se conta da urgência de "despertar a mulher francesa para o mundo que tinha avançado sem ela perceber". Em entrevista a um documentário para a televisão francesa, no final dos anos 60, Lazareff disse, categoricamente, que se sentia "responsável pela nova francesa que se pode ver nas ruas" Numa coletânea de entrevistas com pessoas vinculadas à moda, a editora afirmou que a missão da revista junto às suas leitoras era de "dar às mulheres um mundo que seja para elas tão completo quanto possível [...] de fazer ultrapassar todas as barreiras" (CÉZAN, 1967, p. 121). Ou seja, para essas formadoras da opinião pública francesa, a modernização da sociedade era projeto inadiável.

Numa matéria de dezenas de páginas, em 1951, a Revista Elle tratou de uma questão que foi seu carro-chefe por muitos anos, sempre tentando conquistar a opinião dos leitores. Com a questão-título: “Como está a Haute-couture francesa?" (22/11/1951, p. 22) , a revista analisou a falência da Haute-couture devido ao baixo consumo, após as guerras. Seus consumidores eram de dois tipos: uma clientela particular francesa e estrangeira e, outro, as maisons estrangeiras que compravam o direito de reprodução. Esta última trazia mais lucros, pois "elas pagam $50 \%$ a mais que a clientela particular; os pedidos são executados em medidas padrão (42, 44 e 46) e os pedidos são pagos pontualmente". Porém, se essas vantagens ofereciam maior rentabilidade e menor custo, tais compradores vinham quase que exclusivamente para algumas maisons "onde sopra o gênio criador [...] eles procuravam a ideia".

Destacava, também, que alguns países tinham cessado praticamente suas compras por razões diversas:

A Rússia, a Europa Central, os Bálcãs, a Alemanha, a Áustria são mercados perdidos.

Projética Revista Científica de Design I Universidade Estadual de Londrina I V.2 I N.2 I Dezembro 2011 
Prêt-à-Porter, discussões em torno de seu surgimento e relação com a Alta-Costura francesa A América do Sul é fortemente protegida por barreiras alfandegárias e, ainda, não fornece senão algumas clientes particulares, o que também se encontra no Oriente Próximo.

Para os demais mercados internacionais lembrava que a Itália e a Espanha haviam desenvolvidos suas próprias indústrias de luxo, em detrimento da francesa, sendo que os grandes compradores que restavam vinham dos Estados Unidos, da Bélgica, da Suíça e dos Países Escandinavos.

Por outro ponto de vista, a revista salientava que a situação interna da França era difícil: "um vestido hoje vale 35 a 40 vezes mais que antes da guerra" e, continuava dizendo, que o que se comprava, em 1939, com 2.500 francos franceses, em 1951, exigia 90.000 mil francos franceses. Esses valores eram inadmissíveis porque "nenhum salário, nenhuma renda se multiplicou na mesma proporção". Na análise do perfil da clientela, a matéria julgava que os clientes franceses eram os mesmos de antes, ou seja, pessoas de posses, provindas "das grandes indústrias, grandes bancos, diplomacia e atrizes". Acrescentava neste diagnóstico um exemplo da redução dos negócios através do caso das compras feitas pela família Rothschild, cuja matriarca, em 1939, comprou seis trajes e, em 1951, havia comprado apenas dois. E assim concluía: "Qual que seja o seu orçamento, a cliente de 1951 gasta proporcionalmente menos para se vestir que aquela de 1939". Segundo a revista, principalmente, devia ser ponderado que a cliente de 1951 preferia comprar e manter um carro exclusivo de luxo, fazer belas viagens, dar-se uma máquina de lavar ou um refrigerador, do que dispensar tanto por sua elegância.

Logo, distrações e, sobretudo, conforto agradavam mais a essa mulher de 1951, o que, segundo a revista, demonstrava uma "evolução profunda" que ninguém "saberia honestamente criticar", pois seria isso "o desaparecimento progressivo da mulher boneca, unicamente preocupada com seus chapéus e vestidos".

Se a urgência de mudança da Haute-Couture era grande do ponto de vista da clientela, não era menor pelo da produção. A matéria publicada arrolava os seguintes pontos, dentre a situação crítica que as maisons passavam:

(1)O tempo de um mês a três semanas previsto para a entrega de uma encomenda;

(2)O baixo número de empregados possível de serem mantidos, diante das leis trabalhistas que impediam a demissão, após as grandes estações;

(3)A carga de impostos, como qualquer outra indústria;

(4)A insignificante modernização de seu sistema produtivo, com a manutenção do trabalho artesanal;

(5)A exigência de se estabelecer numa grande avenida e de manter toda uma estrutura de luxo custosa.

Devido a tudo isso, conforme a pesquisa, somente quatro maisons tinham suas contas em dia.

Ao discutir a inadimplência das casas de Haute-couture, ficava visível a defesa que a revista fazia da importância do setor para Paris e a França, no mundo moderno. Conduzindo sua leitora ao argumento que lhe interessava, perguntava: "porque o Ministério das Finanças não exigia o pagamento dos débitos fiscais?", e esclarecia: "Para salvar o emprego de 30 mil trabalhadores diretamente envolvidos com os serviços dessas casas." Nessa argumentação, a revista enfatizava que o governo deveria se empenhar em salvar a Haute-couture francesa, pois, além de todos que trabalhavam nela,

Um vestido assim que sai das mãos de um costureiro parisiense, é muito mais que uma roupa: é uma das expressões mais vivas, das mais gloriosas de nosso espírito 
nacional, na mesma proporção que a pintura ou a música. É uma das formas da beleza, é a prova, a cada ano renovada, que o Mundo não pode passar sem essa faísca misteriosa que nasce dos dedos franceses e que, de 10 metros de musselina, faz uma raridade enquanto outros não fazem senão um vestido.

Reforçava, ainda, que outras maisons existentes no Mundo não eram senão cópias da francesa e que, da mesma forma que eram protegidos os grandes pintores, dever-se-ia salvar a Haute-couture francesa. Lembrava também, que mesmo sendo restritas as exportações da Haute-couture, era devido a elas que os tecidos franceses eram exportados e, o mais importante:

Duas vezes por ano ela atrai milhares de estrangeiros que fazem trabalhar os hotéis, os restaurantes, os teatros, os cabeleireiros, as floristas e de uma maneira geral todo o comércio [...] É preciso dizer que a Haute-couture francesa constitui o elemento atrativo de maior poder de Paris por todas as mulheres estrangeiras [...] A França faz a moda no mundo. Se ela cessa de fazê-lo não é somente os seus vestidos que perdem prestígio e clientela, são seus perfumes, seus prendedores de cabelo, seus tecidos [...] e mesmo suas praias.

Fundamentada nestes argumentos a matéria apresentava, então, a proposta da revista, a qual, nos idos de 1951, era ousada e irreverente.

Para salvar o essencial, o espírito criador, se pode fazer da Haute-couture um tipo de laboratório gigante, animado pelo maior número possível de homens e mulheres dotados; reduzir o número de Maisons e drenar assim toda a clientela em direção àquelas que se constituirão.

Completava sua proposta sugerindo: primeiro, modificar as formas de produção, diminuindo o tempo de trabalho e a quantidade de trabalhadores e, segundo oferecer preço mais adequado, atraindo uma nova clientela. Esta sugestão era exemplificada com a ação de alguns costureiros, que já faziam isso com a experiência da boutique, surgida naquela época.

A fórmula 'boutique' corresponde, cada vez mais e de maneira total, ao modo de vida das mulheres de nosso tempo. E não são somente os costureiros que o constatam: são as costureiras e sua clientela. Elas procuram, cada vez mais, as lojas abertas em Paris todos os dias, onde encontram esse tipo de 'alta-confecção' de bom-gosto e de boa qualidade [...].

E, também, foi citado o exemplo de Jacques Heim, que criou alguns tamanhos-padrões, os quais exigiam apenas adaptações rápidas, diminuindo o desperdício, o tempo de confecção e a mão-de-obra da roupa e, logo, seu preço.

Mediante estas experimentações de mudanças, além de citá-las, a revista analisava as reações provocadas. As clientes que estavam acostumadas ao ready to wear americano aceitavam facilmente a nova proposta de consumo do produto de moda que as boutiques e algumas maisons ofereciam, porém, as francesas, em geral, tinham muita resistência a essas inovações. Se as clientes francesas desconfiavam, a maioria dos criadores afirmava diante desta nova fórmula:

Vocês matam a Haute-couture. Toda criação original exige a liberdade de inspiração. Se devemos fazer duas coleções anuais, pensando em economizar tecido, em evitar as sutilizas do corte, nós perderemos o que faz nossa superioridade sobre os criadores estrangeiros, não poderemos mais nos renovar. 
Mesmo ponderando as opiniões adversas, a revista concluiu a reportagem com um tom otimista, acreditando, talvez, que tivesse argumentado suficientemente para convencer todos. Anunciou, nas últimas linhas, que alguns fabricantes franceses de tecidos, visando combater a concorrência italiana, propunham o patrocínio para alguns criadores, a fim de que eles prestigiassem o tecido nacional (no caso francês) e abrissem o crédito a outros. "Eles podem ajudar alguns a constituir o laboratório a que nos referíamos, onde serão propostos os protótipos, sobre os quais toda a moda mundial se inspirará, e onde todas as últimas mulheres ricas virão se vestir" (p. 34).

Enfim a situação instável para a Haute-Couture estava posta: de um lado, a imprensa francesa exigindo modernização, que acompanhava as demandas de novos grupos de elite, cujos gostos e necessidade de diferenciação eram bem distintos; de outro lado, continuava a existir a clientela tradicional que não queria alterar seu modo de "parecer". Em meio a elas, havia uma Haute-couture que via cada vez mais restrito seu universo de consumidores e suas contas mensais não sendo liquidadas. Completando este quadro de tensões, havia ainda a imagem de Paris e da França, como berço da elegância e de todas as elites mundiais, ameaçada de ruína.

Algo estava em descompasso e a necessidade de mudança estava deflagrada.

\section{Solução encontrada: o prêt-à-porter e a Paris dos novos tempos}

É recorrente a afirmação de que a mudança no sistema produtivo da moda, a partir dos anos 60, tenha ocorrido devido à iniciativa de alguns costureiros em criar o prêt-à-porter. Em muitas destas afirmações, a questão parece ser justificativa desconsiderando todos os fatores históricos inerentes e atribuindo como causa do surgimento do Prêt-à-porter apenas à criatividade de Yves Saint Laurent. Contudo, não é simples assim a abordagem.

Para discutir a questão, pode-se analisá-la a partir de quatro aspectos distintos, dois inerentes à impossibilidade da Haute-Couture continuar sendo o que ela era antes da 2a. Guerra Mundial: a sustentabilidade econômica das maisons; a nova noção de elegância que se impõe nos anos 60; e os outros dois aspectos vinculados à sociedade em geral: o novo perfil das elites e a difusão do consumo do produto de moda.

Primeiramente, o aspecto financeiro das Maisons:

O artigo de ELLE, de 1950, já colocava em evidência a precariedade que as maisons viviam, como se pode ler acima, e isto fazia eco a centenas de outras "denúncias" de que a Haute-couture não poderia permanecer como um reduto fechado a uma centena de mulheres das elites mundiais (ADAM TAILLEUR, 1955; MARIE CLAIRE, 1962; MODES ET TRAVAUX, 1965; JARDINS DES MODES, 1967). Ao lado destas contestações que as maisons estavam sufocadas por suas dívidas, encontram-se diferentes tentativas de contornar a crise da redução da clientela.

Dentre as soluções experimentadas estavam: a parceria com os fabricantes de perfumes, de têxteis e iniciativas como as de Jacques Heim, elogiadas por Elle em 1951 ou as de Jeanne Lanvin e Marcel Dhorme que apresentaram vestidos criados em série com preços mais acessíveis, "mas garantidos pela fama das grandes casas" (O Cruzeiro, 07/10/1950, p. 100). Esta coleção, proposta para o verão de 1950/51, tinha 35 modelos, cujo preço individual variava em torno de 20 mil a 50 mil francos. Esses valores eram acessíveis porque, na mesma época, um vestido de Haute-couture, assinado por Robert Piguet, custava 500 mil francos. Todavia, 
Mara Rubia Sant'anna-Muller

o salário médio anual de um empregado de alto padrão na França de 1951 era de apenas 10.785 francos (BAUDELOT; LEBEAUPIN, 1979, p. 18) e, para se ter um parâmetro em relação à economia brasileira, com valor menor era possível comprar um terreno de $28 \mathrm{mil} \mathrm{m2} \mathrm{em} \mathrm{área}$ nobre de Florianópolis, na mesma época (O Estado, 07/04/1951, p. 4).

Sem dúvida, a questão econômica é bastante flagrante e impeditiva da continuidade da alta-costura, todavia não faltaram iniciativas para reduzir os preços e atrair maior clientela, na medida em que tentaram produzir modelos menos exclusivos e mais baratos. Desta forma, a justificativa econômica para o surgimento do Prêt-à-porter é pouco razoável, na medida em que os preços dos modelos produzidos sob a égide desta nova nomenclatura não ficaram distantes daqueles já propostos por Lanvin e Dhorme em 1950.

Por outro lado, analisando a questão para além dos preços praticados e sua relação com os salários médios de grupos sociais de poder aquisitivo elevado, pode-se questionar: por que propostas, como de Heim ou Lanvin, não vingaram entre os próprios costureiros?

Soluções imediatistas de ampliação da clientela não vingaram entre os próprios costureiros ou mesmo junto a sua clientela mais abastada porque as coleções de "preços módicos" comprometiam a imagem dos criadores e de seus consumidores, que viam sua "arte" e suas aquisições vulgarizadas com os modelos mais "populares". Afinal, as coleções "bom e barato" comprometiam o que distinguia a Haute-Couture: a representação de privilégio, exclusividade e poder. Dior criticou severamente as tentativas de Lanvin e Dhorme, pois: "a Haute-couture é privilégio de bolsas mais favorecidas" (O Cruzeiro, 07/10/1950), em suas próprias palavras.

Sobretudo, havia ainda algo mais, que faz a questão econômica ficar totalmente secundarizada na análise desta problemática.

Não apenas os costureiros eram "vulgarizados" com as coleções mais "populares", como também elas comprometiam a imagem de Paris como berço das elites mundiais. As coleções de baixo valor tornavam de "todos" algo que foi criado e se sustentava como produto de poucos, daqueles que podiam partilhar vestidos assinados, lugares requintados e maneiras exclusivas de viver e de apreciar o belo.

Esta constatação encaminha a um outro ponto da questão, que é bastante relevante para a compreensão de como o surgimento do prêt-à-porter se justifica historicamente: o perfil de consumo da nova elite constituída após a segunda guerra mundial, o que ultrapassa os muros e as possibilidades de reação das maisons.

A nova elite tinha suas origens no capital financeiro e industrial que se multiplicou rapidamente devido aos projetos de reconstrução dos países destruídos com a Guerra, aos Tratados de Paz firmados, aos avanços tecnológicos que geraram novos produtos e necessidades e à ampliação do mercado consumidor mundial, com o fim das restrições alfandegárias.

Seus membros tinham pais que haviam sido simples membros da classe média e, muitos, haviam mesmo passado fome e trabalhado duramente nos primeiros anos de sua vida profissional. Contudo, na medida em que enriqueceram, o passado foi sepultado e foi constituída uma nova elite. Esta elite desejava ser aceita e integrada à tradicional "boa sociedade", pois isto representaria sua afirmação como novo rico; seria o emblema de seu novo status social.

Todavia, a integração almejada, diferente de outros períodos históricos, não combinava com subordinação aos modelos morais e de consumo. O novo grupo social desejava, nesse contato nem sempre desejado ou aceito pela elite tradicional, tornar-se o modelo, impor novos espaços de sociabilidade e projetar-se como inovação, como o grupo competente para enfrentar o "admirável mundo novo". Ele não apenas havia se tornado o grupo de elite dominante economicamente, como atrevia a pensar-se como dominante culturalmente para o

Projética Revista Científica de Design I Universidade Estadual de Londrina I V.2 I N.2 I Dezembro 2011 
Prêt-à-Porter, discussões em torno de seu surgimento e relação com a Alta-Costura francesa novo mundo que construía com seu espirito empreendedor e sua paixão pelo novo.

Assim, os padrões de bom gosto e consumo do grupo de elite antecessor precisavam ser suplantados. Para este grupo social a Haute-Couture trazia o signo de todo um passado que não devia ser mais glorificado (SANT'ANNA, 2005; HOBSBAWN, 1995).

Originalidade, versatilidade, criatividade e jovialidade são termos fortes no perfil deste novo grupo de elite.

Portanto, a sociedade que se constituía nos anos 50 defrontava-se como uma nova elite, o que implicava, no âmbito da Haute-Couture, a necessidade de rever os valores que exaltava, especialmente o da elegância, cultivado deste o seu surgimento como alento das elites. Tem-se, a partir dessa evidência social, um terceiro ângulo de análise: a nova noção de elegância.

Como emblema da elegância que a Haute-Couture cultivou, pode-se citar o modelo Corola de Dior, mundialmente conhecido, em 1947. O grande volume da saia e sua altura se compunham, sob a noção clássica de equilíbrio estético, com um corpete bastante estruturado, acompanhado de salto alto, luvas e chapéus, os quais deveriam ser usados por um corpo magro, de cintura estreita. Além de esbelta, a mulher que vestia este tipo de modelo devia ser capaz de um gestual delicado, onde mãos finas agiam discretamente, pernas longas caminhavam com destreza e todo o seu ser proporcionava o espetáculo de uma mulher refinada. Segundo Banaïm, Dior tentou com sua coleçao de 1947 condenar ao desaparecimento a parisiense que durante a guerra trabalhou e circulou de bicicleta, "reabilita a 'mulher flor' contra a bicicletista de ombros largos como de lutadores de boxer" (BANAïM, 1999, p. 100). A tendência lançada por Dior deflagrou uma luta comercial e cultural entre a França conservadora, aquela que apoiou o governo ocupacionista, e a cultura norte-americana com suas divas ousadas, vestidas em calças cigarettes, fulmando e vivendo independetemente.

Da elegância corola, feito para mulheres "flor", um outro conceito precisava surgir para a mulher dinâmica e nada dependente dos anos 60 .

Um conceito mais arrojado foi proposto para a elegância nos sixties, ao sabor da sociedade que o admirava e o havia fomentado. Este teve seu eixo central na inovação. Ao longo dessa década, o novo e o extravagante foram ressignificados como irreverência juvenil e competência para adaptar-se aos desafios de uma sociedade que se pensava à beira da autorrealização. Aos poucos, os modelos glamourosos ficaram restritos às festas de gala, e o adjetivo "sofisticado" tornou-se a conotação mais apropriada de elegância. O novo adquiria seu "glamour" por uma combinação equilibrada entre arrojo, originalidade e inovação, sem recair sobre o luxo e a ideia de delicadeza anteriores (SANT'ANNA, 2006).

Em meio a esta nova configuração social, a haute-couture ver-se-ia constrangida se permanecesse conservadora, se continuasse a alimentar o desejo de distinção de uma elite que beirava à caduquice, enquanto uma nova elite, endinheirada e jovem exigia leveza e distinção como sinônimo de liberdade, de descontração e não de fragilidade e submissão. A vitoria da cultura norte-americana (BODY-GENDROT, 1996) sobre a tradição francesa exigia uma nova Haute-Couture e assim, no seio de sua própria produção, a Haute-Couture tinha que converter seus valores mais caros, fosse para sobreviver financeira ou simbolicamente.

Desta forma, pode-se analisar, finalmente, o quarto aspecto deste estudo: a difusão do consumo do produto de moda, a partir dos anos 60 .

O baby boom ocorrido nos anos 50, acompanhado de toda uma formação discursiva que valorizava os avanços tecnológicos anunciados, como também buscava vencer a tristeza anterior com o entusiasmo diante do futuro, gerou, em breves palavras, uma confiança no novo e nos jovens que não têm precedentes (HOBSBAWN, 1995). Esta sociedade amante do novo aproximou-se cada vez mais do conceito de moda e passou a qualificar-se como consumidora 
Mara Rubia Sant'anna-Muller

apta ao seu consumo, antes privilégio das elites (LIPOVETSKY, 1991). Contudo, não seriam o sistema produtivo e a elegância propagada pela tradicional Haute-Couture eficientes para atender àquela demanda, pois, como visto acima, os costureiros sentiam-se pouco à vontade para voltar-se para esta nova clientela, por medo de perverterem seu ofício e, ao mesmo tempo, descontentarem sua clientela fiel.

Também há de se considerar que os grupos sociais menos abastados haviam, desde muito tempo, criado sua própria forma de consumo do novo.

Desde o surgimento das indústrias de confecção, no século XIX, essas tinham um mercado consumidor muito mais amplo que aquele retido pela Haute-couture. As maisons, com seu espetáculo publicitário, detinham para si a áurea de criadoras, enquanto as confecções, lidando com um mercado de menor poder aquisitivo e que tinha menores exigências de exibição, ofereciam mercadorias destinadas a durar diversas estações. Não havia concorrência entre os dois polos, e a grande maioria da população mundial, com seus diferentes grupos e poderes aquisitivos, ora adquiria os produtos da confecção industrial, ora recorria à costura doméstica, e quem podia mais recorria aos ateliês de costura e alfaiataria que cada cidade possuía, com maior ou menor prestígio. As tendências que nessas condições se seguiam eram aquelas difundidas pelas revistas de moda, as quais adaptavam os modelos divulgados da Haute-couture aos bolsos de suas leitoras/leitores, quando não propunham outros, elaborados por seus desenhistas ou modelistas. Pode-se considerar que, ao lado da Haute-couture e todo o seu glamour, sempre existiu uma rua que se vestiu como pode e como lhe era agradável .

A grande distinção que se impôs, no contexto dos anos 60 , foi a autoconfiança propalada pela nova geração que pretendeu mesmo desdenhar das tendências de moda que a Haute-Couture apresentava. Mary Quant, em 1955, como uma jovem atenta aos anseios de seus colegas, insere-se no mercado de moda propondo uma alternativa aos modelos mais convencionais disponíveis. Ela declarava, como filha de seu tempo, que se atribuía a missão de vestir os jovens distantes das gerações precedentes (SIMON, 2009).

A referenciada "inversão da pirâmide de difusão de moda" deve ser atribuída ao questionamento que a sociedade fez de todas as autoridades, inclusive a da Haute-couture que ditava os caminhos por onde o novo devia passar e o que seria elegante. Esta nova sociedade passou a reivindicar a posse do novo, do bem feito e diferente. Clamar pelo novo e original tornou-se uma prerrogativa civil de todos.

Enfim, a mudança vivida na haute-couture está relacionada intimamente à criação de um novo mercado consumidor resultante de uma série de transformações históricas, como vistas até aqui, o que desencadeou sua crise financeira e sua revisão da noção de elegância propagada. Todavia, a questão permanece aberta de por que o prêt-à-porter foi criado em meio a todas estas mudanças. Seu surgimento não foi uma resposta automática à sociedade e suas mudanças nem à Haute-Couture com sua crise. Seu surgimento pode ser analisado a partir de seu papel na representação de Paris como capital da moda.

Com a quebra da Haute-Couture, Paris precisaria repensar as fissuras de seu espelhamento da elegância mundial e se "atualizar" ao tipo de elite e sociedade que os novos tempos pós-guerra constituíram. Uma questão de política nacional estava posta: abrir-seia mão de tudo que a Haute-Couture representava da França no exterior e para os próprios franceses ou se buscaria uma nova Haute-Couture?

Na matéria de 1951, Elle, como ja analisado, não foi defendida a extinção da Hautecouture, porque, antes de tudo, "Um vestido assim que sai das mãos de um costureiro parisiense, é muito mais que uma roupa: é uma das expressões mais vivas, das mais gloriosas de nosso espírito nacional [...]" (ELLE, 26/11/51, p. 34). Sua proposta era de reformulação, concentração de esforços e exaltação do "espírito nacional" através de "um tipo de laboratório

Projética Revista Científica de Design I Universidade Estadual de Londrina I V.2 I N.2 I Dezembro 2011 
Prêt-à-Porter, discussões em torno de seu surgimento e relação com a Alta-Costura francesa gigante animado pelo maior número possível de homens e mulheres dotados [...]". Logo, é na intertextualidade dessa representação da Haute-couture como expressão ímpar da criatividade e especialidade francesa e de suas relações com a necessidade de modernização de um país que havia perdido sua hegemonia mundial, que se interpreta o surgimento do prêt-à-porter. Era preciso propor uma forma de produção do "novo" que combinasse a exaltação do ato criativo do costureiro, a atração de uma clientela suficientemente grande para manter os negócios em superávit e a fidelidade da elite mundial aos seus balcões. Com isso tudo, talvez fosse possível preservar Paris e seus salões como os Campos Elíseos da elite de todos os cantos do planeta.

Combinar todos estes objetivos ao mesmo tempo foi um desafio que se superou não por uma ação consciente e operante de um governo ou de uma iniciativa privada. Foi a sociedade que, nos seus jogos de poder e transformação, foi ofertando possibilidades que os atores sociais testaram e aprovaram. A sociedade dos anos 60 , com suas práticas sociais e demandas, foi além das expectativas e propôs mesmo uma outra noção de costureiro, de elegância e de moda.

A estrutura morosa com que a Haute-couture produzia seus modelos desde o século XIX tornou-se incompatível com o novo ritmo de consumo, assim como a tradição que ela pretendia cultuar não correspondia mais ao perfil de sua nova clientela. Acompanhando essas incompatibilidades, costureiros como Dior, Rochas entre tantos outros da "velha guarda", à medida que se aposentaram, morreram ou faliram, deram vez a outros profissionais à frente das maisons, cujos desejos e talentos abriram novos caminhos para as criações.

Os desejos artísticos destes novos costureiros, forjados por uma sociedade que passou a desconfiar de todas as autoridades e saberes, a amar todas as inovações e originalidades como nenhuma outra, tornaram-se, por sua vez, incompatíveis com as necessidades da clientela mais tradicional que desejava vestir-se dentro de um padrão de normalidade. Na cabeça destes novos costureiros, a Haute-Couture não podia mais se ocupar de vestir corpos, a ela cabia uma missão mais inovadora e irreverente.

Paco Rabanne foi, como outros surgidos no final dos anos 60 , um dos primeiros criadores de fato, pois apareceu num momento em que a Haute-couture já podia dispor de não vestir a elegância, mas unicamente de criar. Ele ensaiou os voos criativos mais inesperados dos anos posteriores. Vôos que alimentaram, em sua relação dialógica com a sociedade de moda, as extravagâncias que ela estava disposta a saborear. Então, tanto costureiros como o sistema da moda tornaram-se independentes da tradicional Haute-Couture e esta, sem seus esteios, desapareceu para tornar-se outra: o campo da experimentação estética sobre a plasticidade de um corpo em movimento.

Compreende-se assim que a criação do prêt-à-porter atendeu aos interesses de preservar a imagem de Paris como berço das elegantes do mundo quando essas reconfiguradas por novos poderes e valores, multiplicaram-se e apresentaram mais autonomia de decisão e desejo de consumo. O prêt-à-porter, que nada tem a ver com o ready wear americano e nem escamoteia sua origem francesa, através de seus preços proibitivos e sua aura de produto distintivo, foi um caminho espetacular de adaptação da Haute-couture a uma imagem de instituição moderna e atenta aos interesses econômicos de suas empresas. O prêt-à-porter garantiu a reprodução do poder pela aparência, assim como liberou os costureiros para, no âmbito da criação, darem os seus voos de pura estética conceitual, criando assim um outro papel para a Haute-couture.Essa nova modalidade de organizaçao da criaçao de moda não foi incumbida de atender a demanda de produtos de moda que as ruas faziam e nem surgiu como demanda dela. O prêt-à-porter nunca a atendeu diretamente e nem se ocupou dela. Como nova autoridade para ditar o que seria tendência de moda nas futuras estações, ele passa a ser

Projética Revista Científica de Design I Universidade Estadual de Londrina I V.2 I N.2 I Dezembro 2011 
Mara Rubia Sant'anna-Muller

um esteio onde outros estilistas e criadores de moda vêm buscar inspiração para traduzir as demandas dos diferentes públicos consumidores.

Para vestir a população sequiosa de produtos de moda, apaixonada e seduzida pelo novo, Daniel Hechter, Michèle Rozier, Christine Bailley, Emmanuelle Khanh foram alguns dos mais importantes profissionais de moda que surgiram no contexto de reformulação do sistema de moda, vivido nos anos 60 (SIMON, 2009). Mais do que novos nomes, eles encarnavam nova dinâmica de produção da aparência exaltada. Eles não almejavam o estrelato como o grande costureiro gozava. Contratados por grandes indústrias de confecção ou possuindo a sua própria, eles passaram a conceber o traje a ser usado no dia-a-dia jovialmente, o qual era reproduzido para o consumo de centenas de clientes no mundo inteiro. Mary Quant, com sua loja Bazar, foi consagrada por sua iniciativa neste tipo de proposta de produção e consumo do produto de moda.

A grande proposta para vestir os grupos sociais em ascensão e absorvidos pela paixão do novo foi a concepção de um novo tipo de comércio, no qual se combinou criatividade, originalidade, tratamento personalizado e preços acessíveis. Tal inovação chama-se "boutique" e a quem desejar investigar a tal "inversão da pirâmide de difusão de moda", sugere-se que comece por investigar essa nova forma de comércio, onde, mais do que roupas, vendeu-se personalidade.

Portanto, ao prêt-à-porter, diante do novo sistema de produção de tendências sazonais, não coube responsabilidades revolucionárias, mas apenas a autoridade, que outrora a HauteCouture possuía, de ditar os caminhos do novo a serem cultuados e a noção de elegância/ sofisticação a serem perseguidos. Se há neste novo termo algum sinal de ruptura, ele o é em relação à própria imagem que a Haute-couture parisiense restringia para si

Assim, o prêt-à-porter, um nome cuja sonoridade nada deixa em débito à sua origem francesa e ao glamour que devia perpetuar, foi o processo de difusão da moda mais adequado para substituir a Haute-couture, que ressignificava seu papel na imagética de Paris e das elites que a consumiam. O que estava em jogo era a manutenção de Paris como espelho da elegância mundial, sem a vulgarização ou "apelação" dos modelos, para uma clientela mais vasta.

Concluindo, a sociedade voltada para o consumo e o espetáculo, fomentada pelos processos históricos vivenciados a partir do segundo quinquênio dos anos 50 , levaram à expansão da sociedade de moda (LEFEBVRE, 1991) e, dessa maneira, à consolidação do parecer como lógica social. Esta consolidação do ethos moda levou o campo de produção das mercadorias, vinculadas à dimensão estética, a adquirir um mercado altamente afoito e competitivo . Esse aspecto sócio-econômico dinamizou o setor da produção do vestuário e exigiu-Ihe mais do que a oferta de uma roupa, a oferta de um desejo travestido em tecidos, formas e cores. Tal demanda foi atendida pela dinâmica dos "pequenos" das grandes marcas de confeç̧ão, da publicidade e, especialmente, da forma de comercialização dos produtos de moda no formato boutique.

Logo, este estudo defende que o surgimento do prêt-à-porter justifica-se a partir da imagem que interessava à Paris, como à Haute-couture ali produzida, manter quando o mundo tornava-se outro a sua volta. O novo modelo de produção das marcas luxuosas foi uma opção bem sucedida para preservar a nação francesa como a única detentora da genialidade no campo da elegância e, logo, a mais autorizada para criar o novo.

\section{Notas}

${ }^{1}$ Período em que Paris e parte do norte francês foram ocupadas pelas forças militares alemães, na Segunda Guerra Mundial. 
Prêt-à-Porter, discussões em torno de seu surgimento e relação com a Alta-Costura francesa "Ver Elias (1994), sobre o conceito de "configuraçao social" e Hobsbawn (1995), a respeito das mudanças estruturais a que se faz menção neste texto.

${ }^{3}$ Ver as seguintes publicações sobre a história da revista: Perier e Bauby (1995); Baudot e Demachy (2002). ${ }^{4}$ Palestra sobre suas experiências profissionais, realizada em outubro de 2003, junto ao Groupe de l'Histoire de la Mode, filiado ao Institut d'Histoire du Temps Présent - CNRS. Paris.

5Programa televisivo: « Vivre aujourd'hui - la femme et la beauté ». 1970.

${ }^{6}$ Todas as citações posteriores, sem indicação pertencem à mesma referência.

7Usar a terminologia inglesa para se referir aos anos 60 é provocativo, pois expressa com maior precisão as vinculações do novo conceito com a juventude e o moderno, espelhados pela cultura norte-americana.

${ }^{8} \mathrm{O}$ estudo de Ártemis Yagou (2005) sobre as atividades do Athens Design Center, escritório norte-americano de design dos anos 60, cuja missão autoproclamada era de educar empresários e consumidores a reconhecer o bom design (good design), evidencia a mesma noção de elegância implicada a outros setores que não o do vestuário.

${ }^{9}$ Ver a respeito, MUSEE DE DIOR (1996). Todo livro se ocupa em apresentar por meio de entrevistas e biografias a história do desenho de moda nos periódicos de maior tiragem francesa e internacional, sendo que todos os grandes desenhistas da época confirmam sua atribuição de criadores de modelos para as revistas em que trabalhavam.

${ }^{10}$ Abordagem semelhante ver: Ormen-Corpet (1999). A autora analisa como os álbuns de família servem de estudo das transformações operadas nas formas vestimentares.

${ }^{11}$ Um equívoco grave que a tradução para o português do livro "A roupa e a moda", de James Laver (1993, p. 261).

${ }^{12}$ Lucila Fernandez Uriarte (2005) analisa as repercussões desta "sociedade de moda" na América Latina.

\section{Referências}

ANÚNCIO da Imobiliária A.L.Alves. Jornal O Estado, 7 abr. 1951, p. 4.

BANAÏM, Laurence. Le pantalon: une histoire en marche. Paris: Les Editions de l'Amateur, 1999.

BAUDELOT, Christian; LEBEAUPIN, Anne. Les salaires de 1950 à 1975. Economie et statistique, Paris, n. 113, p. 15-22, 1979. Disponível em: <http://www.persee.fr/web/ revues/ home/prescript/article/estat_0336-1454_1979_num_113_1_4224>. Acesso: 27 jun. 2011.

BAUDOT, François; DEMACHY, Jean. Elle nos années 60/70. Paris: Filipacchi, 2002.

CÉZAN, Claude. La mode phénomène humain. Paris: Privat, 1967.

ELIAS, Nobert. A sociedade dos indivíduos. Rio de Janeiro: Jorge Zahar, 1994.

ELLE. Où en est la Haute-Couture Française? Paris. v. 313, p. 22, 1951.

ELLE. Néogravure. 1965. France Editions et Publications, 1966-1970, jan./dez. 1950- 
Mara Rubia Sant'anna-Muller

1970.

FERNANDEZ-URIARTE, Lucila. Post modernity from Cuba. Journal of Design History, Oxford, v. 18, n. 3, p. 245-255, 2005.

BODY-GENDROT, Sophie. Uma vida privada francesa segundo o modelo americano. In: AIRES, Philippe. História da vida privada. São Paulo: Cia das Letras, 1996. v. 5.

HOSBAWM, Eric. A era dos extremos. São Paulo: Companhia das Letras, 1995.

JARDIN DES MODES. Editions Saint-Florentin, jan./dec. 1967.

LAVER, Jamers. A roupa e a moda: uma história concisa da moda. São Paulo: Companhia das Letras, 1993.

LEFEBVRE, Henri. A vida cotidiana no mundo moderno. São Paulo: Ática, 1991. v. 1.

LIPOVETSKY, Gilles. O império do efêmero. São Paulo: Companhia das Letras, 1991.

MARIE CLAIRE. Editor. E. Desfosses Néogravure. Paris, jan./dec. 1962.

MODES ET TRAVAUX. Paris: Editions Edouard Boucherit, jan./dec. 1965.

MUSEE DE DIOR. Images de mode 1940-1960. Hommage à M. Bernard Blossac. Granville: Musée Christian Dior, 1996.

ORMEN-CORPET, Catherine. L'album de famille, almanach des modes: fotografias de Joël Laiter. Paris: Hazan, 1999.

O CRUZEIRO. Revolução branca na moda. Rio de Janeiro: Diários Associados, 7 out. 1950.

PERIER, Anne-Marie; BAUBY, Jean Dominique. Elle: nos 50 premières années. Paris: Filipacchi, 1995.

ROCHAS, Marcel; MATHAN Jacques. Vingt-cinq ans d'élégance à Paris. Paris: Pierre Tisné, 1951.

SANT'ANNA, Mara Rúbia. Poder e aparência: novas sociabilidades urbanas em Florianópolis de 1950 a 1970. 2005. Tese (Doutorado em História) - Instituto de Filosofia, Letras e Ciências Humanas, Universidade Federal do Rio Grande do Sul, Porto Alegre.

Elegância e sociedade, ser elite entre 1950 e 1970 . Modapalavra, Florianópolis, v. 4, p. 99-108, 2006.

SIMON, Marie. La mode 1945 - 1975. Paris: Aubanel, 2009.

VEILLON, Dominique. Moda e guerra: um retrato da França ocupada. Rio de Janeiro: Jorge Zahar, 2004.

VIVRE aujourd'hui - la femme et la beauté. Jacques Frémontier, 1970. (Documentário de TV)

Projética Revista Científica de Design I Universidade Estadual de Londrina I V.2 I N.2 I Dezembro 2011 
Prêt-à-Porter, discussões em torno de seu surgimento e relação com a Alta-Costura francesa YAGOU, Artemis. The Athens Design Centre: (1961-1963). Journal of Design History, v. 18, n. 3, p. 269-283, 2005. 